\title{
Transmission Potential and Severity of COVID-19 in Pakistan
}

\author{
Muhammad Asif Rasheed ${ }^{1 \#}$, Sohail Raza ${ }^{2 \#^{*}}$, Muhammad Khalid Rashid ${ }^{3 \#}$ \\ ${ }^{1}$ Department of Biosciences, COMSATS University Islamabad, Sahiwal Campus, Sahiwal, Pakistan \\ ${ }^{2}$ Department of Microbiology, University of Veterinary and Animal Sciences, Lahore, Pakistan \\ ${ }^{3}$ Department of Economics, Government College of Science, Wahdat Road, Lahore, Pakistan
}

\section{* Corresponding author}

Dr. Sohail Raza PhD

Assistant Professor

Department of Microbiology

University of Veterinary and Animal Sciences

Lahore

Tel: +92-3006524483

Email: sohail.raza@uvas,edu.pk

\# Equally contributing authors.

\section{Abstract}

As of 26 March 2020, Pakistan had 1179 cases of COVID-19, with most 421 cases from Sindh, 394 cases, 131 cases, 123 cases, 84 cases, 25 cases and 01 cases from Punjab, Balochistan, Khyber Pakhtunkhwa, Gilgit-Baltistan, Islamabad Capital Territory, and Azad Jammu and Kashmir respectively. Travel-related cases were the main source of SARS-CoV-2 infection during the early phase of the pandemic in Pakistan. Nevertheless, cases of local virus transmission are increasing day by day. As of 26 March 2020, nine deaths have been reported from COVID-19. The case fatality rate is $0.8 \%$, which is less compare to China, Italy, USA, and Iran. The SIR (Susceptible-Infected-Recovered) model of epidemiological analysis predicts that almost 90 million population will be infected in the coming days with $5 \%$ critical cases that need health care facilities. However, the Pakistan health care system cannot provide services to this much population. Hence, we need to act timely to reduce this number by restricting local transmission of the disease. This can be done by mass testing, quarantine, isolation and social distancing of the active coronavirus cases in Pakistan. Moreover, better communication between the authorities is very much required to control disease transmission.

Keywords: COVID-19, Pakistan, Economic Losses, Disease Spread, SARS-CoV-2

Running Title: Epidemiology of COVID-19 in Pakistan 


\section{Introduction}

In December 2019, a cluster of pneumonia cases emerged in Wuhan city, the capital of Hubei Province, China. Later on, the causative agent was identified as a novel Coronavirus and now named as severe acute respiratory syndrome Coronavirus 2 (SARS-CoV-2) [1]. More than 97 percent of individuals show symptoms within 11.5 days of exposure [2]. The disease symptoms include fever, cough, myalgia, diarrhea, and dyspnea [3]. The COVID-19 has a case-fatality rate of 2-3\%, with higher rates among elderly patients and patients with co-morbidities [4]. A respiratory droplet from the infected patients is the main source of transmission, and it can also transmit through contact. The SARS-CoV-2 has a higher spreading ability than SARS-CoV with R0 (Basic reproduction number) range from 2.2 to 3.58 [3]. Despite the efforts of the Chinese government to contain the virus spread through lockdown, it rapidly spread to other cities in China, neighboring countries and countries where people moved from China [5]. The COVID-19 is declared a global health emergency by world health organization (WHO) on January 31, 2020. Moreover, the WHO declared COVID-19 a pandemic disease as well.

As of 26 March 2020, COVID-19 has affected 198 countries with more than 0.4 million cases and more than 21000 deaths throughout the globe. Till now, COVID-19 has reached to all the continents except Antarctica. Out of seven Indian subcontinent countries, Pakistan has the largest outbreak with 1106 reported cases and 08 deaths. In January 2020, the Government of Pakistan took measures to check the passengers coming from china for the sings of COVID-19 infection [6].

\section{First Case Report in Pakistan}

In Asia, Iran reported the most number of COVID-19 cases after china. Each year, thousands of Pakistani people visit Iran for religious and cultural purposes. As the number of COVID-19 cases begins to soar, Pakistan closed its border with Iran on February 23, 2020 [7], but hundreds of Pakistanis managed to get back in any way, either rerouting through Afghanistan to Pakistan or by other means. On February 26, government officials of Pakistan confirmed the fist two cases of coronavirus; one from Karachi and other from Islamabad. Both cases were returned from Iran recently. To prevent the spread of the infection, officials decided to quarantine the tourists coming from Iran in Taftan city, a border town in Balochistan, Pakistan [8].

\section{Disease Progression in Pakistan}

On 29 February 2020, two more cases of COVID-19 were confirmed by the Government officials. One of the cases was from Karachi while the other was from federal areas of the country. On 02 March 2020, one more case of a 45 years old woman from Gilgit-Baltistan, who recently visited Iran was confirmed. On March 8, 2020, 9th case was reported in 50 years old man from Karachi. The very next day, 
Pakistan reported nine new cases in Karachi and reaches the total to 16 cases of COVID-19. Among these cases, Sindh had the highest number of cases where the total cases were 13. Five of the new patients had traveled from Syria and some other patients returned from London. Three new cases were confirmed on 10 March, including one in Hyderabad and the first case in Quetta, Balochistan.

On 11 March, a second case was confirmed in 14 years old boy from Skardu Gilgit- Baltistan. The next day, the third case in Gilgit-Baltistan was confirmed in 31 years old resident of district Shigar. The resident had a recent travel history to Iran. On 13 March, The first case of local virus transmission was confirmed from Sindh in 52 years old patient who had local travel history. On this day, six more cases were reported in Taftan and one in Sindh that made the total number of COVID-19 patients to 28. On the next day, two new cases were detected in Karachi while one was confirmed in Islamabad. On 15 March, five new cases were confirmed in Karachi. Among these, four had the travel history while the fifth had the disease through the local transmission. On the same day, the first case was reported in Lahore, Punjab. The patient was recently returned from the United Kingdom. Moreover, the government officials also confirmed 11 new patients in Sindh and 6 in Balochistan. On 16 March, there was a sharp increase in the number of newly confirmed cases with 116 in Sindh, 15 in Khyber Pakhtunkhwa and 3 in Balochistan. With this sharp increase, the number of confirmed cases across the country reached 187 . By the next day, countrywide cases reached 237 with twenty-five new patients in Punjab, twelve in Sindh and four in Islamabad. By March 18, a total of 302 cases were confirmed in Pakistan with the first case in Azad Kashmir. On the same date, the first two deaths due to COVID-19 infection were reported in Khyber Pakhtunkhwa. The ages of the patients were 36 and 50 years. On March 20, the third death was reported in Sindh.

By 26 March 2020, the total number of confirmed cases were 1179 and 09 deaths were reported as described in Figure 1A and 1B. Among these cases, 421 cases were from Sindh with 1 death and 14 recoveries, 394 cases were from Punjab with 02 deaths and 03 recoveries, 131 cases were from Balochistan with 1 death and 0 recovery, 121 cases were from Khyber Pakhtunkhwa with 03 deaths and 02 recoveries, 84 cases were from Gilgit-Baltistan with 02 death and 0 recovery, 25 cases were from Islamabad with 0 death and 0 recovery and 01 cases was from Azad Kashmir with 0 recoveries and 0 death as described in Figure 1C and 2A ( The data of all COVID-19 cases retrieved from the Government of Pakistan Official dashboard control by National Institute of Health (NIH) Islamabad, Pakistan http://covid.gov.pk/). 


\section{Figme 1}

A

Total Cases, Total Deaths and Total Recoveries (as of 26 March, 2020)
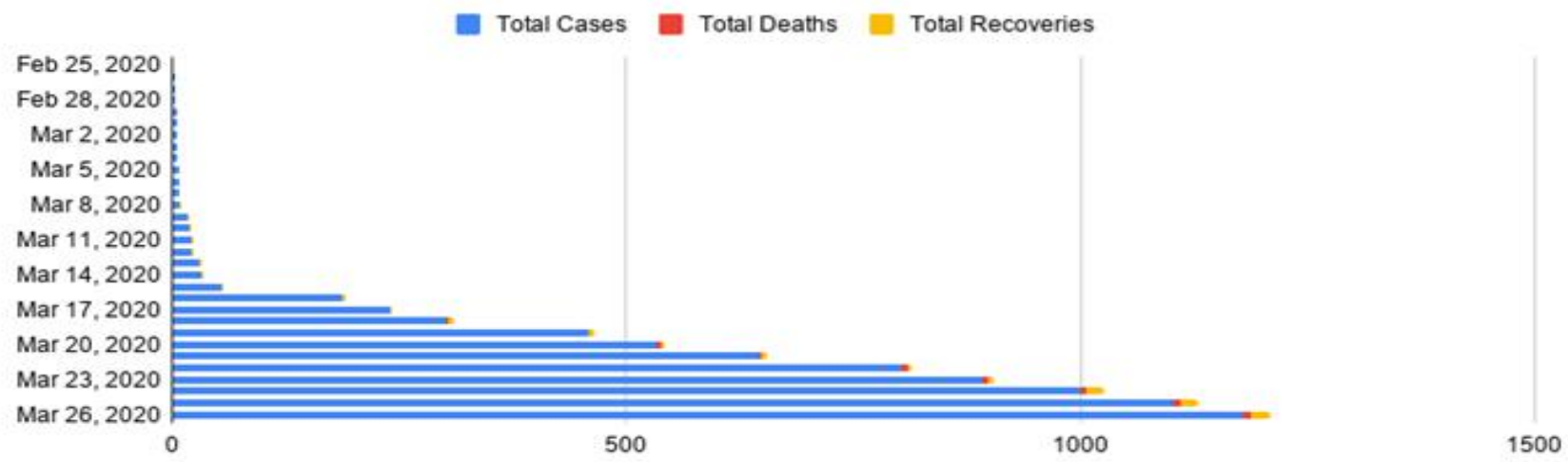

$\mathbf{B}$

Total Cases vs. Date (as of 26 March, 2020)

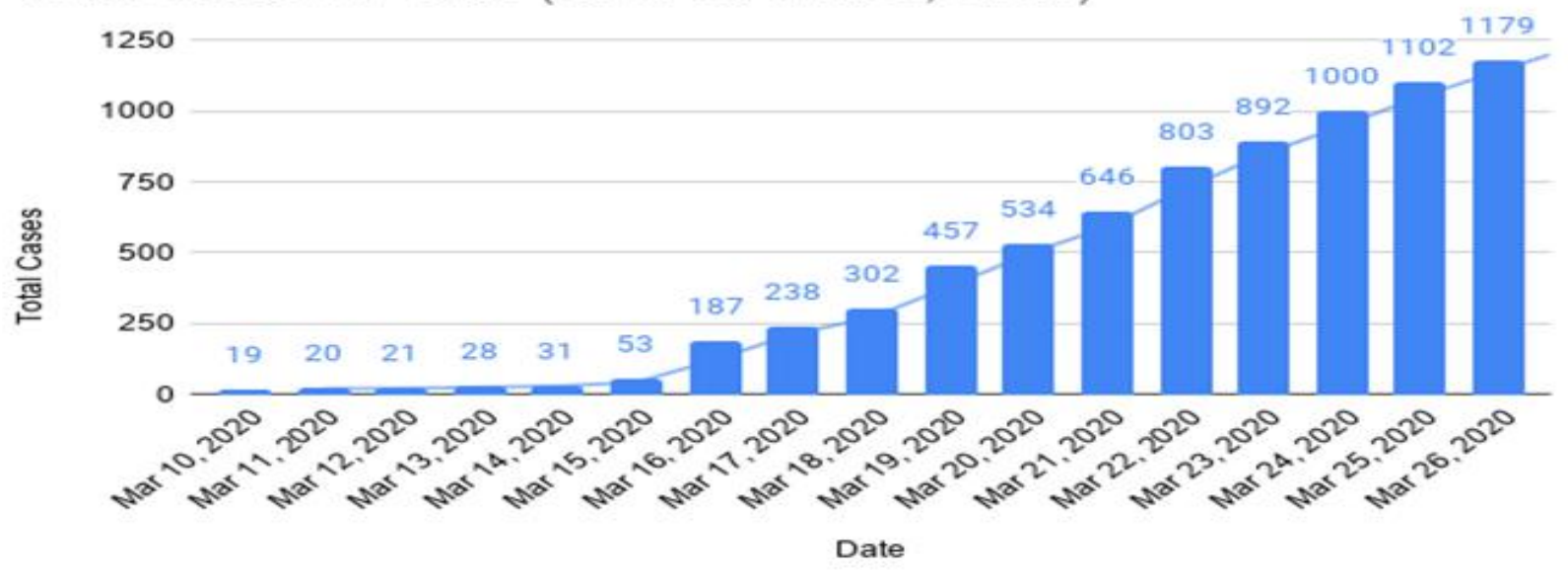

C

COVID-19 CASES IN PAKISTAN (26 March,2020)

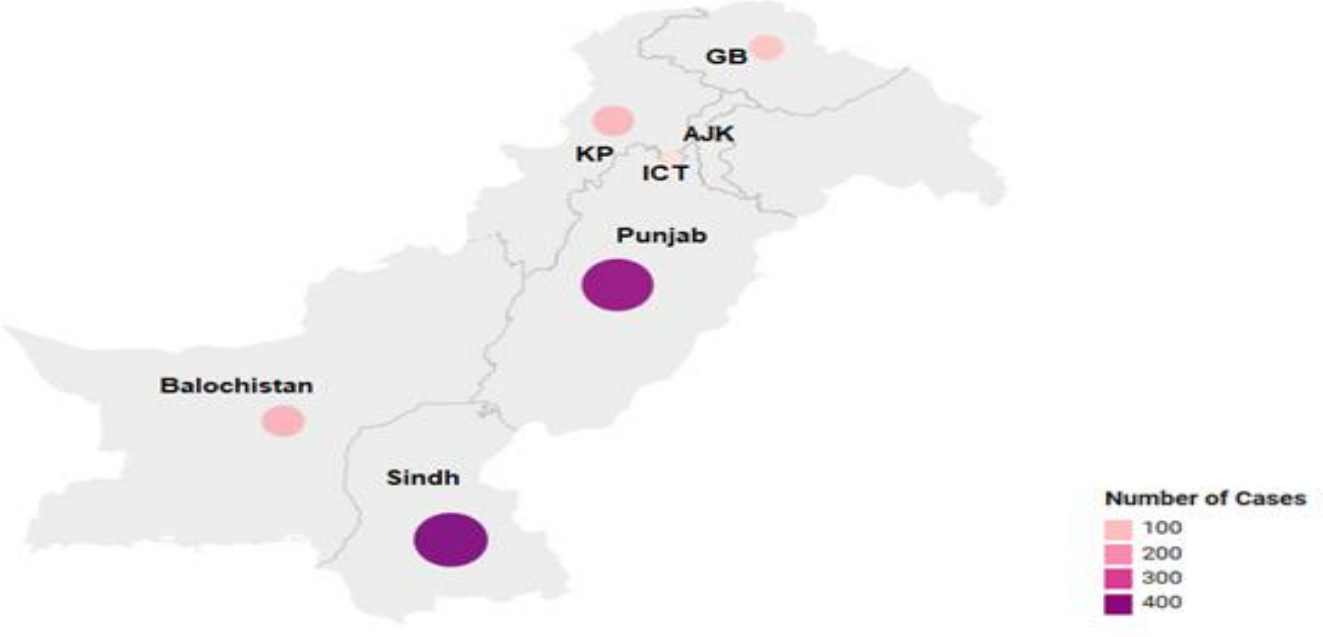

Figure 1. Total Number of COVID-19 cases in Pakistan. (A) Total number of cases, deaths, and recoveries up to 26 March 2020. (B) Total rise in the number of cases with the time (C) Distribution of COVID-19 cases in Pakistan 


\section{Case Fatality Rate in Pakistan}

The reported case fatality rate in china was $2.3 \%$ that is substantially lower than Italy (7.2\%), Spain (7.3\%) and Iran (7.6\%) as of March 26, 2020[9]. Till now, the case fatality rate in Pakistan is $0.8 \%$, which is considerably low among the countries having cases $\geq 1000$ (Figure 3 ). The risk of dying from COVID-19 has a direct relationship with the age of the individual. The risk of dying increases with age and co-abnormalities. Hence, most of the deaths from COVID-19 observed in individuals older than 60 years, particularly those with chronic abnormalities like cardiac diseases [10]. Pakistan has only $4.44 \%$ individuals age 65 years or above that is considerably less compared to China (12.34\%), Italy (22.08\%), Spain (18.49\%) and Iran (5.87\%) [11]. This data suggests that the countries having more population of older age have a higher case fatality rate of COVID-19. As Pakistan has only a small population of age 65 years or above, the case fatality rate of COVID-19 will remain less in Pakistan with proper medical care as compared to China, Italy, and Spain.

\section{Epidemiological Prediction of the expected number of infected cases in Pakistan using SIR Model}

The SIR model is one of the epidemiological models that can be used to predict the number of indivisibles who can be infected by a contagious disease in a population over a period of time. This model consists of three compartments; S number of susceptible individuals, I number of infectious individuals, and $\mathrm{R}$ number of immune/recovered individuals. For prediction, online free available Hans Nesse $\begin{array}{lllll}\text { Global Health } & - & \text { SIR }\end{array}$ (http://www.public.asu.edu/ hnesse/classes/sir.html?Alpha $=0.023 \& B e t a=0.01 \&$ initialS $=24$ ) was used. The total population of Pakistan (207 million) is assumed to be susceptible to this disease. The total number of infected cases in 1179 and recovered cases 21 were used in this prediction. Considering the rate of recovery $\gamma$ value 0.125 was used and $\beta$ value 0.535 was used for the prediction as described in Figure 2 B.

The data predicts that nearly 90 million of the population is likely to become infected at the $35^{\text {th }}$ Day. It is pertinent to mention here that $81 \%$ of COVID-19 infection cases are of mild nature (with or without mild symptoms), 14\% develop a severe disease that requires treatment and 5\% cases are critical that mostly involve the individuals with co-morbidities like hypertension [4]. Considering this, 5\% of the infected populations that make 4.5 million of the individuals are predicted to come and use the hospital facility.

Moreover, the results of the regression line based on Figure 1B show that the number of confirmed coronavirus cases has a positive and significant relationship with the number of suspected coronavirus cases $(\mathrm{Y}=-3.86+1.021 \mathrm{X})$. It shows that with one unit change in the active case, the 
confirm case will rise by 1.021 cases. It may also be used for the future forecast. For example, if, in Pakistan, the number of suspected cases increases by 5000, 10000 and 20000 cases then the number of confirmed cases will rise by 5101, 10206 and 20416 cases respectively. Furthermore, with the help of the second estimated regression line $(Z=-0.208+0.006 Y)$, we may conclude that the number of deaths due to coronavirus disease has a positive relationship with the number of confirmed cases. It may forecast similarly as if we assume 5000, 10000 and 20000 confirmed cases in Pakistan then the expected number of deaths will be 30,60 and 120 respectively.

Unfortunately, the Pakistan health care system is not much developed to handle this huge number of patients that will ultimately result in the collapse of the healthcare system in Pakistan [12]. To reduce these huge numbers, the state should play its role through policy interventions. These interventions include contact tracing, isolation, quarantine or any other means that reduce the transfer of the disease. This will ultimately reduce the $\beta$ value which eventually results in the reduction of the expected number of COVID-19 infected individuals.

\section{Trace, Test and Treat model of South Korea}

Broad tracing with extensive testing without lockdown was crucial in preventing the spread of COVID-19 in South Korea. The country employed one of the biggest and well-organized programs along with Singapore, Vietnam, and Taiwan. Extensive screening of the population was conducted for COVID19 infections and isolates the infected person along with tracing and quarantines those who were in contact with the infected individuals. The extensive and abrupt actions taken by the authorities in South Korea have been successful in reducing the spread of the outbreak regardless of not quarantine entire cities. South Korea has tested 270000 individuals that equal to 5200 tests per million inhabitants [13]. As per the data acquired from the National Institute of Health, Islamabad till March 26, 2020, Pakistan had tested only 6449 cases. This number is very low considering the population of the country in comparison to South Korea and China. As discussed earlier that more than $80 \%$ of the infected individuals exhibit mild signs or no signs. Hence, fewer tests mean a large number of infected individuals are out in open and may become a source for spreading the virus. In addition to this, inadequate testing and contact tracing may lead to economic disaster, once the lockdown is lifted [14]. 


\section{Figme 2}

ICT, Punjab, Sindh, KPK, Balochistan, GB, AJK (as of 26 March 2020)

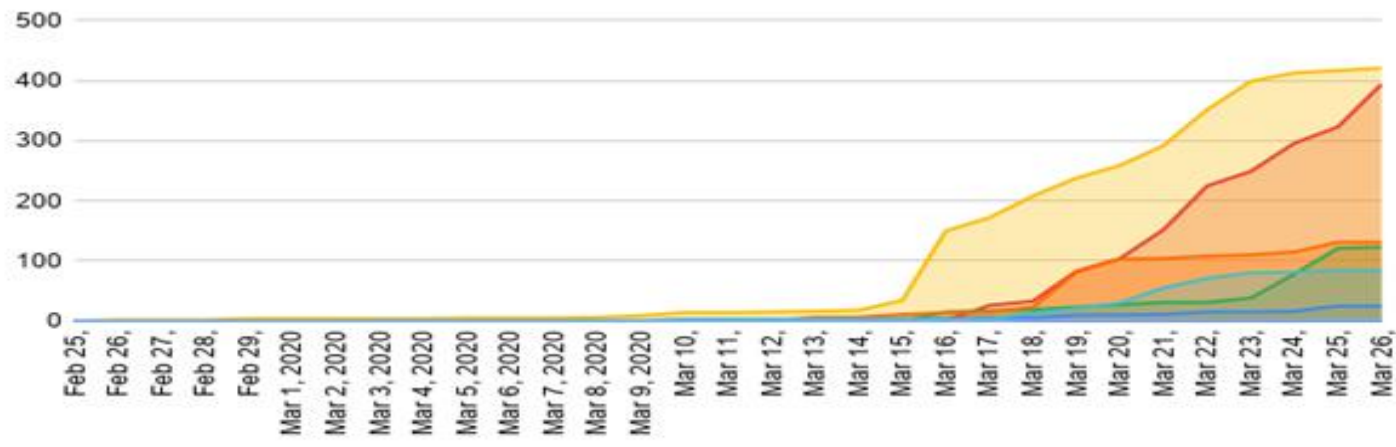

$\mathbf{B}$

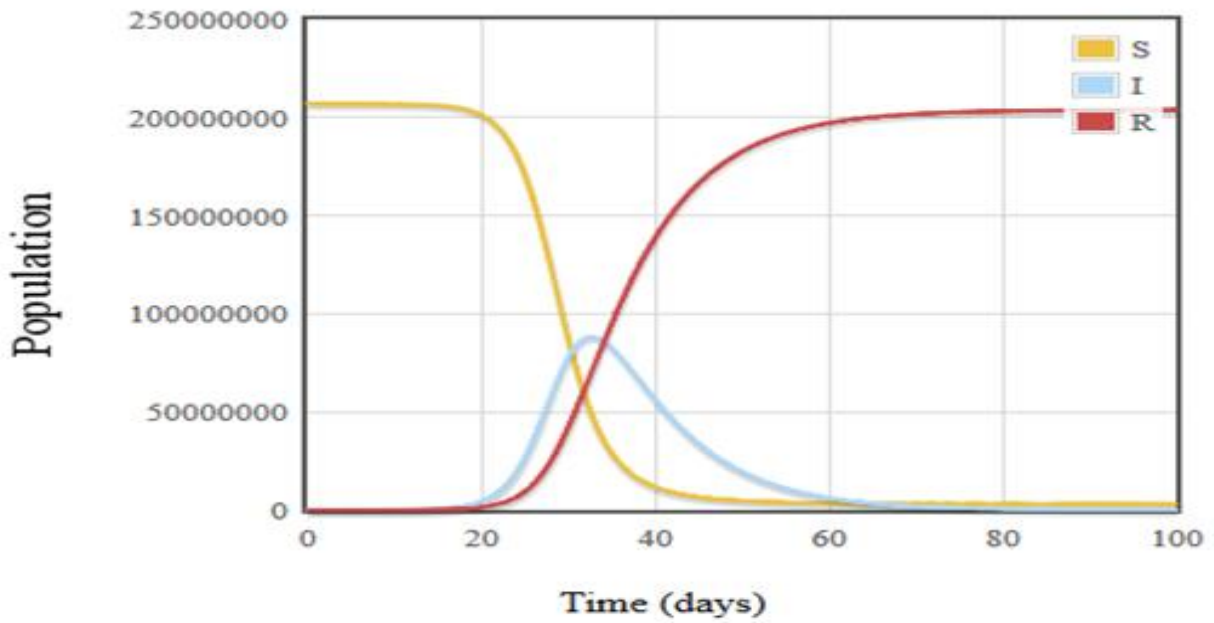

C

\begin{tabular}{|c|c|c|c|c|c|c|}
\hline 1. Austrafia & V L H S T & G V Y Y H & G F S A L & H R R Y L & E V R Q I & K D F G G \\
\hline 2. Brazil & V L H S T & G V Y Y H & G F S A L & H R S Y L & E V R Q I & K D F G G \\
\hline 3. China & V L H S T & G V Y Y H & G F S A L & H R S Y L & E V R Q I & K D F G G \\
\hline 4. Finland & V L Y S T & G V Y Y H & G F S L & H R S Y L & E V R Q I & K D F G G \\
\hline 5. India & V L H S T & $\mathrm{G} \mathrm{V}-\mathrm{YH}$ & G F S A L & H R S Y L & E V I Q I & K D F G G \\
\hline 6. Italy & V L H S T & G V Y Y H & G F S A L & H R S Y L & E V R Q I & K D F G G \\
\hline 7. Japan & V L H S T & G V Y Y H & G F S A L & H R S Y L & E V R Q I & K D F G G \\
\hline 8. Nepal & V L H S T & G V Y Y H & G F S A L & H R S Y L & E V R Q I & K D F G G \\
\hline 9. Pakistan & V L H S T & G V Y Y H & G F S A L & H R S Y L & E V R Q I & K D F G G \\
\hline 10. South Korea & V L H S T & G V Y Y H & G F WA L & H R S Y L & E V R Q I & K D F G G \\
\hline 11. Spain & V L H S T & G V Y Y H & G F S A L & H R S Y L & E V R Q I & K D F G G \\
\hline 12. Sweden & V L H S T & G V Y Y H & G F S A L & H R S Y L & E V R Q I & $\mathrm{KDCG} \mathrm{G}$ \\
\hline 13. Taiwan & V L H S T & G V Y Y H & G F S A L & H R S Y L & E V R Q I & K D F G G \\
\hline 14. USA & V L H S T & G V Y Y H & G F S A L & H R S Y L & E V R Q I & K D F G G \\
\hline 15. Viet Nam & $\begin{array}{c}\text { V L H S T } \\
\text { 1ि } \\
\text { Position } 49\end{array}$ & $\begin{array}{c}\text { G V Y Y H } \\
\text { Position } 144\end{array}$ & $\begin{array}{c}\text { G F S A L } \\
\text { 1̂ि } \\
\text { Position 221 }\end{array}$ & $\begin{array}{c}\text { H R S Y L } \\
\text { 1. } \\
\text { Positioa } 247\end{array}$ & $\begin{array}{c}\text { E V R Q I } \\
\text { 1 } \\
\text { Position } 407\end{array}$ & $\begin{array}{c}\text { K D F G G } \\
\text { Position } 797\end{array}$ \\
\hline
\end{tabular}

Figure 2. Analysis of COVID-19 in Pakistan. (A) Province wise increase in the number of cases. (B) The SIR epidemiological analysis is for the prediction of suspected, Infected and Recovered population from COVID-19. (C) MSA of spike glycoprotein of Coronaviruses from different countries 


\section{Expected economic losses due to COVID-19 in Pakistan}

As for as economic growth of Pakistan is a concern, there can be 12.3 to 18.53 million layoffs out of those employed in different sectors. Moreover, researchers distributed the lingering crisis into three stages i.e. Stage-I, Stage-II, and Stage-III. They estimated 22 billion PKR, 186.86 billion PKR and 260.9 billion PKR loss per month for stage-I stage-II stage-III respectively. The cost may increase if the period of lockdown would extend. Moreover, there is a sharp decline in domestic demand, decreased tourism and business travel, export-imports and production linkages and supply disruptions. Nowadays, Pakistan is somewhere between Stages I and II which can go between Stage II and III if the numbers of confirmed cases continue to grow exponentially. In the case of complete lockdown (Stage III), there is a possibility to reach the number of layoffs to above 18 million [15].

\section{Comparison of Pakistani COVID-19 virus with other countries}

To compare the virus of Pakistani origin with other countries, the sequences of surface glycoprotein were retrieved from the National Center for Biotechnology Information (NCBI) nucleotide database (https://www.ncbi.nlm.nih.gov/nuccore). These sequences belong to coronaviruses of different countries including Pakistan. Altogether, 15 sequences of different countries were retrieved.

The retrieved sequences were aligned to check the similarities and differences of the retrieved sequences against the reference sequence. For pairwise alignment, the surface glycoprotein sequence of coronavirus from Pakistan was taken as the reference sequence. All the retrieved sequences were aligned against the reference coronavirus sequence using the BLAST algorithm (https://blast.ncbi.nlm.nih.gov/Blast.cgi). Moreover, the multiple sequence alignment of all the retrieved sequences was performed to check the similarities and differences among the sequences. The multiple sequence alignment of all the sequences was performed by the Muscle algorithm using Molecular Evolutionary Genetics Analysis (MEGA) software version 6.06. The pairwise alignment of all the retrieved sequences was performed against the reference coronavirus sequence from Pakistani origin.

According to the results, the sequence similarity against reference sequence was found maximum with Vietnam, USA, Taiwan, Spain, Nepal, Japan, Italy, China and Brazil as mentioned in the results of multiple sequence alignment Figure 1C. Moreover, the least similarity was found with the Indian coronavirus. Furthermore, the results of multiple sequence alignment are shown in. According to the results, little variation was found in sequences of coronaviruses of different countries including Finland, Sweden, Australia, South Korea, and India. Moreover, a deletion was also found in Indian sequence at position 144. As the sequences of SARS-CoV-2 are $99.98 \%$ genetically similar that predicts a great prospect for the success of the future vaccine. 


\section{Conclusion}

As the epidemiological data suggests, a huge number of population is susceptible to be affected by COVID-19 infection. The government has already closed the educational institutions and the partial lockdown has been imposed in the country. Efforts should be made to reduce the spread of the virus through social distancing, contact tracing, isolation and quarantine measures. Most importantly, massive testing should be done in the potential population to point out the silent spreader of the virus to reduce the disease spread. There should be a strong communication along with data and resource sharing between central and provincial authorities. Our frontline army is now our healthcare professionals. Steps should be taken to reduce the risk of healthcare providers being infected from the patient by providing recommended personal protective equipment (PPE).

\section{Acknowledgments}

No acknowledgments 


\section{References}

1. Guan WJ, Ni ZY, Hu Y, Liang WH, Ou CQ, He JX, Liu L, Shan H, Lei CL, Hui DSC, Du B, Li LJ, Zeng G, Yuen KY, Chen RC, Tang CL, Wang T, Chen PY, Xiang J, Li SY, Wang JL, Liang ZJ, Peng YX, Wei L, Liu Y, Hu YH, Peng P, Wang JM, Liu JY, Chen Z, Li G, Zheng ZJ, Qiu SQ, Luo J, Ye CJ, Zhu SY, Zhong NS (2020) Clinical Characteristics of Coronavirus Disease 2019 in China. N Engl J Med. https://doi.org/10.1056/NEJMoa2002032

2. Lauer SA, Grantz KH, Bi Q, Jones FK, Zheng Q, Meredith HR, Azman AS, Reich NG, Lessler J (2020) The Incubation Period of Coronavirus Disease 2019 (COVID-19) From Publicly Reported Confirmed Cases: Estimation and Application. Ann Intern Med. https://doi.org/10.7326/M20-0504

3. Wu D, Wu T, Liu Q, Yang Z (2020) The SARS-CoV-2 outbreak: what we know. Int J Infect Dis. https://doi.org/10.1016/j.ijid.2020.03.004

4. Wu Z, McGoogan JM (2020) Characteristics of and Important Lessons From the Coronavirus Disease 2019 (COVID-19) Outbreak in China: Summary of a Report of 72314 Cases From the Chinese Center for Disease Control and Prevention. JAMA. https://doi.org/10.1001/jama.2020.2648

5. Porcheddu R, Serra C, Kelvin D, Kelvin N, Rubino S (2020) Similarity in Case Fatality Rates (CFR) of COVID-19/SARS-COV-2 in Italy and China. J Infect Dev Ctries 14:125-128. https://doi.org/10.3855/jidc. 12600

6. Ayaz Gul (2020) Pakistan Begins Screening Travelers From China for Coronavirus. In: Voice Am.

7. Patrick Wintour (2020) Turkey and Pakistan close borders with Iran over coronavirus deaths. The Guardian

8. Zia ur-Rehman MA-H and ITM (2020) 'God Will Protect Us': Coronavirus Spreads Through an Already Struggling Pakistan. N. Y. Times

9. Onder G, Rezza G, Brusaferro S (2020) Case-Fatality Rate and Characteristics of Patients Dying in Relation to COVID-19 in Italy. JAMA. https://doi.org/10.1001/jama.2020.4683

10. Lloyd-Sherlock P, Ebrahim S, Geffen L, McKee M (2020) Bearing the brunt of covid-19: older people in low and middle income countries. BMJ 368:m1052 . https://doi.org/10.1136/bmj.m1052

11. (2020) The World Factbook

12. Faran Khalidand Ahmed Nadeem Abbasi (2018) Challenges Faced by Pakistani Healthcare System: Clinician's Perspective. J Coll Physicians Surg 28:899-901

13. Dennis Normile (2020) Coronavirus cases have dropped sharply in South Korea. What's the secret to its success? Science

14. Javad M Goraya (2020) Is Pakistan testing enough people for COVID-19? Geo Opin.

15. Muhammad Nasir NF\& MK (2020) Sectoral Analysis of the VulnerablyEmployedCOVID-19 and the Pakistan's Labour Market. PIDE COVID-19 Bull 4:1-6 